\title{
Origin of Microglia: Current Concepts and Past Controversies
}

\author{
Florent Ginhoux ${ }^{1}$ and Marco Prinz ${ }^{2,3}$ \\ ${ }^{1}$ Singapore Immunology Network (SIgN), Agency for Science, Technology and Research (A*STAR), \\ Singapore 138648 \\ ${ }^{2}$ Institute of Neuropathology, University of Freiburg, 79106 Freiburg, Germany \\ ${ }^{3}$ BIOSS Centre for Biological Signalling Studies, University of Freiburg, 79106 Freiburg, Germany \\ Correspondence: florent_ginhoux@immunol.a-star.edu.sg; marco.prinz@uniklinik-freiburg.de
}

Microglia are the resident macrophages of the central nervous system (CNS), which sit in close proximity to neural structures and are intimately involved in brain homeostasis. The microglial population also plays fundamental roles during neuronal expansion and differentiation, as well as in the perinatal establishment of synaptic circuits. Any change in the normal brain environment results in microglial activation, which can be detrimental if not appropriately regulated. Aberrant microglial function has been linked to the development of several neurological and psychiatric diseases. However, microglia also possess potent immunoregulatory and regenerative capacities, making them attractive targets for therapeutic manipulation. Such rationale manipulations will, however, require in-depth knowledge of their origins and the molecular mechanisms underlying their homeostasis. Here, we discuss the latest advances in our understanding of the origin, differentiation, and homeostasis of microglial cells and their myelomonocytic relatives in the CNS.

\begin{abstract}
$M_{\text {icroglia are the resident macrophages of }}^{\text {ing }}$ Mthe central nervous system (CNS), which are uniformly distributed throughout the brain and spinal cord with increased densities in neuronal nuclei, including the Substantia nigra in the midbrain (Lawson et al. 1990; Perry 1998). They belong to the nonneuronal glial cell compartment and their function is crucial to maintenance of the CNS in both health and disease (Ransohoff and Perry 2009; Perry et al. 2010; Ransohoff and Cardona 2010; Prinz and Priller 2014).
\end{abstract}

Two key functional features define microglia: immune defense and maintenance of CNS homeostasis. As part of the innate immune system, microglia constantly sample their environment, scanning and surveying for signals of external danger (Davalos et al. 2005; Nimmerjahn et al. 2005; Lehnardt 2010), such as those from invading pathogens, or internal danger signals generated locally by damaged or dying cells (Bessis et al. 2007; Hanisch and Kettenmann 2007). Detection of such signals initiates a program of microglial responses that aim to resolve the injury, protect

Editors: Ben A. Barres, Marc R. Freeman, and Beth Stevens

Additional Perspectives on Glia available at www.cshperspectives.org

Copyright (C) 2015 Cold Spring Harbor Laboratory Press; all rights reserved; doi: 10.1101/cshperspect.a020537

Cite this article as Cold Spring Harb Perspect Biol 2015;7:a020537 
the CNS from the effects of the inflammation, and support tissue repair and remodeling (Minghetti and Levi 1998; Goldmann and Prinz 2013).

Microglia are also emerging as crucial contributors to brain homeostasis through control of neuronal proliferation and differentiation, as well as influencing formation of synaptic connections (Lawson et al. 1990; Perry 1998; Hughes 2012; Blank and Prinz 2013). Recent imaging studies revealed dynamic interactions between microglia and synaptic connections in the healthy brain, which contributed to the modification and elimination of synaptic structures (Perry et al. 2010; Tremblay et al. 2010; Bialas and Stevens 2013). In the prenatal brain, microglia regulate the wiring of forebrain circuits, controlling the growth of dopaminergic axons in the forebrain and the laminar positioning of subsets of neocortical interneurons (Squarzoni et al. 2014). In the postnatal brain, microglia-mediated synaptic pruning is similarly required for the remodeling of neural circuits (Paolicelli et al. 2011; Schafer et al. 2012). In summary, microglia occupy a central position in defense and maintenance of the CNS and, as a consequence, are a key target for the treatment of neurological and psychiatric disorders.

Although microglia have been studied for decades, a long history of experimental misinterpretation meant that their true origins remained debated until recently. Although we knew that microglial progenitors invaded the brain rudiment at very early stages of embryonic development (Alliot et al. 1999; Ransohoff and Perry 2009), it has now been established that microglia arise from yolk sac (YS)-primitive macrophages, which persist in the CNS into adulthood (Davalos et al. 2005; Nimmerjahn et al. 2005; Ginhoux et al. 2010, 2013; Kierdorf and Prinz 2013; Kierdorfet al. 2013a). Moreover, early embryonic brain colonization by microglia is conserved across vertebrate species, implying that it is essential for early brain development (Herbomel et al. 2001; Bessis et al. 2007; Hanisch and Kettenmann 2007; Verney et al. 2010; Schlegelmilch et al. 2011; Swinnen et al. 2013). In this review, we will present the latest findings in the field of microglial ontogeny, which provide new insights into their roles in health and disease.

\section{HISTORICAL PERSPECTIVES ON MACROPHAGES AND MICROGLIA}

In 1969, the original phagocyte classification systems based on the work of Metchnikoff and Ehrlich, and later Aschoff (Aschoff 1924; Minghetti and Levi 1998; Gordon and Taylor 2005; Kaufmann 2008), were superseded by the concept of the mononuclear phagocyte system (MPS) (van Furth and Cohn 1968; van Furth et al. 1972), a term that is still used today (Geissmann et al. 2010). The MPS today includes circulating monocytes in the bloodstream ("inflammatory" or Ly-6C ${ }^{+}$CCR2 ${ }^{+} \mathrm{CX}_{3} \mathrm{CR} 1^{\text {lo }}$ monocytes and "patrolling" or Ly-6C ${ }^{-} \mathrm{CCR} 2^{-}$ $\mathrm{CX}_{3} \mathrm{CR} 1^{\text {hi }}$ monocytes in mouse), as well as dendritic cells and macrophages from both lymphoid and nonlymphoid organs. In this context, macrophages are the resident phagocytic cells in lymphoid tissues (spleen, lymph nodes) and nonlymphoid tissues, such as the brain (microglia), liver (Kupffer cells), lung (alveolar macrophages), bone (osteoclasts), kidney (kidney macrophages), and skin (Langerhans cells). Of note, epidermal Langerhans cells are a unique cell population in the sense that, although arising from macrophage progenitors, they acquire unique dendritic cell features on final differentiation compared with other macrophage populations (Ginhoux and Merad 2010; Hoeffel et al. 2012). At these sites, macrophages contribute to steady-state tissue homeostasis via the clearance of apoptotic cells and the production of growth factors, but, on infection, they become activated to phagocytose pathogens and produce inflammatory cytokines, as they are equipped with a broad range of pathogenrecognition receptors (Gordon 2002). Although the MPS has been a useful framework for considering phagocyte biology, it also led to the assumption that all tissue macrophages are identical in origin and function. However, this assumption has been challenged in recent years, especially in the case of microglia (Ginhoux et al. 2010; Hoeffel et al. 2012; Schulz et al. 2012).

It has taken more than 150 years of research for microglia to be formally recognized as a separate and specialized macrophage population in the CNS with distinct developmental origins. 
del Río-Hortega was the first to clearly identify a small population of phagocytic, migratory cells within the CNS, which he proposed were of mesodermal origin (del Río-Hortega 1932). Some years later, he introduced the term "microglial cell," and refined his description of these cells as the nonneuronal, nonastrocytic element of the CNS, distinct from neurectodermal oligodendroglia and oligodendrocytes (del Río-Hortega 1939), which constitute the macroglia. Despite some controversies on microglia origin from either the mesoderm or the ectoderm in the history of microglial study (Rezaie and Male 2002; Chan et al. 2007; Ginhoux et al. 2013), several investigators followed del RíoHortega's hypothesis and presented evidence supporting a mesodermal origin of microglia in light of their morphological and phenotypic similarities with macrophages, first by coupling light/electron microscopy and immunohistochemistry, which allowed identification of parallel morphological features of macrophages and microglia at various stages of development (Murabe and Sano 1982, 1983), and, second, by showing that microglial cells were recognized by antisera raised against monocyte/macrophage antigens (Hume et al. 1983; Perry et al. 1985).

\section{MARKERS OF MICROGLIA}

Because of their mesodermal origin, microglia share many features with other myeloid cell types in the body. Observations of the phenotypic similarities between circulating monocytes, tissue macrophages, and microglia were first reported $\sim 30$ years ago in immunohistochemical studies, which showed microglial expression of macrophage markers, including F4/ 80, Fc receptor, and CD11b, in mouse (Perry et al. 1985) and, later, in human (Akiyama and McGeer 1990).

As the tissue-resident macrophage of the CNS, murine microglia have since been confirmed to express multiple macrophage markers, including the colony-stimulating factor (CSF)-1 receptor (CSF-1R, CD115), the integrin $\mathrm{CD} 11 \mathrm{~b}$, the surface glycoproteins $\mathrm{F} 4 / 80$, the inhibitory immune receptor CD200R, the surface enzyme tyrosine-protein phosphatase non- receptor-type substrate or $\mathrm{CD} 172 \alpha$, the fractalkine receptor $\mathrm{CX}_{3} \mathrm{CR} 1$, and the calcium-binding protein lba-1 (Prinz and Mildner 2011). However, few markers, which are specific to microglia, have been identified. CD39 (ectonucleoside triphosphate diphosphohydrolase) gene expression has recently been proposed to enable distinction of microglia from their peripheral relatives (Butovsky et al. 2012). Recent studies also reported that microglia have a unique transcriptomic signature, which distinguishes them from other CNS cells and peripheral macrophages or monocytes (Gautier et al. 2012; Chiu et al. 2013), and express a unique cluster of transcripts encoding proteins for sensing endogenous ligands and microbes, defined as the sensome (Hickman et al. 2013). Microglia also express lower levels of the panhematopoietic marker CD45 compared with tissue macrophages, which also permits their discrimination from monocytes in the bloodstream, whereas the hemoglobin scavenger receptor CD163 enables distinction from perivascular macrophages in the steady state (Dijkstra et al. 1985; Serrats et al. 2010).

\section{THE YS ORIGIN OF MICROGLIA}

The evident phenotypic similarities between microglia and other macrophage populations led to ready acceptance of the notion of their myeloid origin, although the true identity of microglial progenitors remained controversial until recently. Initial studies described the presence of microglial cells during early development, suggesting that microglia arise from embryonic progenitors. These progenitors were first proposed by del Río-Hortega to be meningeal macrophages infiltrating the brain during early embryonic development. However, the majority of the scientific community at that time, including del Río-Hortega himself, believed that microglia could also be derived from blood monocytes. Monocytes are indeed recruited to the neonatal and adult brain, in the latter case, most often under inflammatory conditions, where they can differentiate into microglia-like cells. These observations long supported the prevailing viewpoint that blood- 
circulating monocytes represented microglial progenitors, replacing those seeding the brain during embryonic development. In fact, until recently, the most consensual hypothesis was that embryonic and perinatal hematopoietic waves of microglial recruitment and differentiation occurred in the CNS.

When del Río-Hortega first described microglia, he also noted their presence in early development and proposed that, near this time, they might initially arise from mesodermal cells of the pia mater, the innermost layer of the meninges (the membranes surrounding the CNS). He reported the "migration of embryonic corpuscles from the pia into the nerve centres," but simultaneously proposed that "microglia may eventually arise from other related elements, chiefly the blood mononuclears," based on the similarities in morphology and phagocytic activity between microglia and monocytes (del Río-Hortega 1939). These two statements were the founding of the "origin of microglia" controversy that was to last for the next 50 years. Later, the observation that the brain rudiment already contains microglia at E9.5 of the $20 \mathrm{~d}$ of murine embryonic development (Alliot et al. 1991, 1999) forced developmental neuroscientists to delve more deeply into the complex subject of embryonic hematopoiesis. Our current understanding of the multifaceted process of embryonic hematopoiesis was extensively reviewed (Cumano and Godin 2007; Orkin and Zon 2008). The appearance of microglia in the neuroepithelium at E9.5 days suggested that their precursors might originate from the YS (Fig. 1). The murine embryonic YS produces early primitive macrophages and erythrocytes as part of the process of "primitive hematopoiesis," occurring from E8.5, as opposed to the generation of definitive hematopoietic stem cells (HSCs), which occurs in the aortagonad-mesonephros (AGM) region of the embryo around E10.5. These AGM-derived HSCs then migrate to the fetal liver (FL) and bone marrow (BM) and differentiate therein into all lineages, including monocytes, macrophages, and lymphocytes, which are generated as part of "definitive hematopoiesis" (Bertrand et al. 2005; Cumano and Godin 2007). In addition, from E8.25, multilineage erythromyeloid progenitors (EMP) and lymphomyeloid progenitors also emerge in the YS as a "second wave," which is already considered as part of the definitive hematopoietic wave but called the transient definitive stage. The contribution of such progenitors to macrophage populations via a fetal monocyte intermediate remain to be investigated. HSC-derived myeloid cells, such as monocytes, are produced abundantly in the FL only from E12.5/E13.5 (Fig. 1), days after the initial colonization of the brain rudiment by YS macrophages at E9.5. Of interest, a population of maternally derived macrophages can be found in the YS of the embryo as early as E7.5. This population, however, subsequently decreases in number, becomes almost undetectable at E9.0, and is later absent in the embryo (Bertrand et al. 2005; Kierdorf et al. 2013a).

At E8.5-9.0, the first immature macrophages are found in the YS (Takahashi et al. 1996; Lichanska and Hume 2000), and they develop through a nonmonocytic pathway (Takahashi et al. 1996; Lichanska and Hume 2000). The first macrophage-like cells with an amoeboid shape appear in the rodent neuroepithelium at a similar time point (Ashwell 1990; Ashwell and Waite 1991; Chan et al. 2007) and were suggested to be the precursors of microglial cells (Alliot et al. 1999). A clear requirement for the circulatory system for brain colonization by YS macrophages was determined using E9.5-10 Ncx-1 ${ }^{-7-}$ embryos, which have no functional blood circulation (Koushik et al. 2001), and were found to lack microglial progenitors, as well as other fetal macrophages, despite normal YS hematopoiesis (Ginhoux et al. 2010). At E13.5, when the FL is already the primary hematopoietic organ and the main site of HSC expansion and differentiation (Lichanska and Hume 2000), microglial precursors can be detected in significant numbers within the lining of the fourth ventricle (Chan et al. 2007). As a result of the finding that tissues, such as the CNS, contain YS-derived macrophages, but not HSC or maternal macrophages, it became reasonable to believe that microglia originate from YS macrophages rather than from HSC in the FL or BM. 


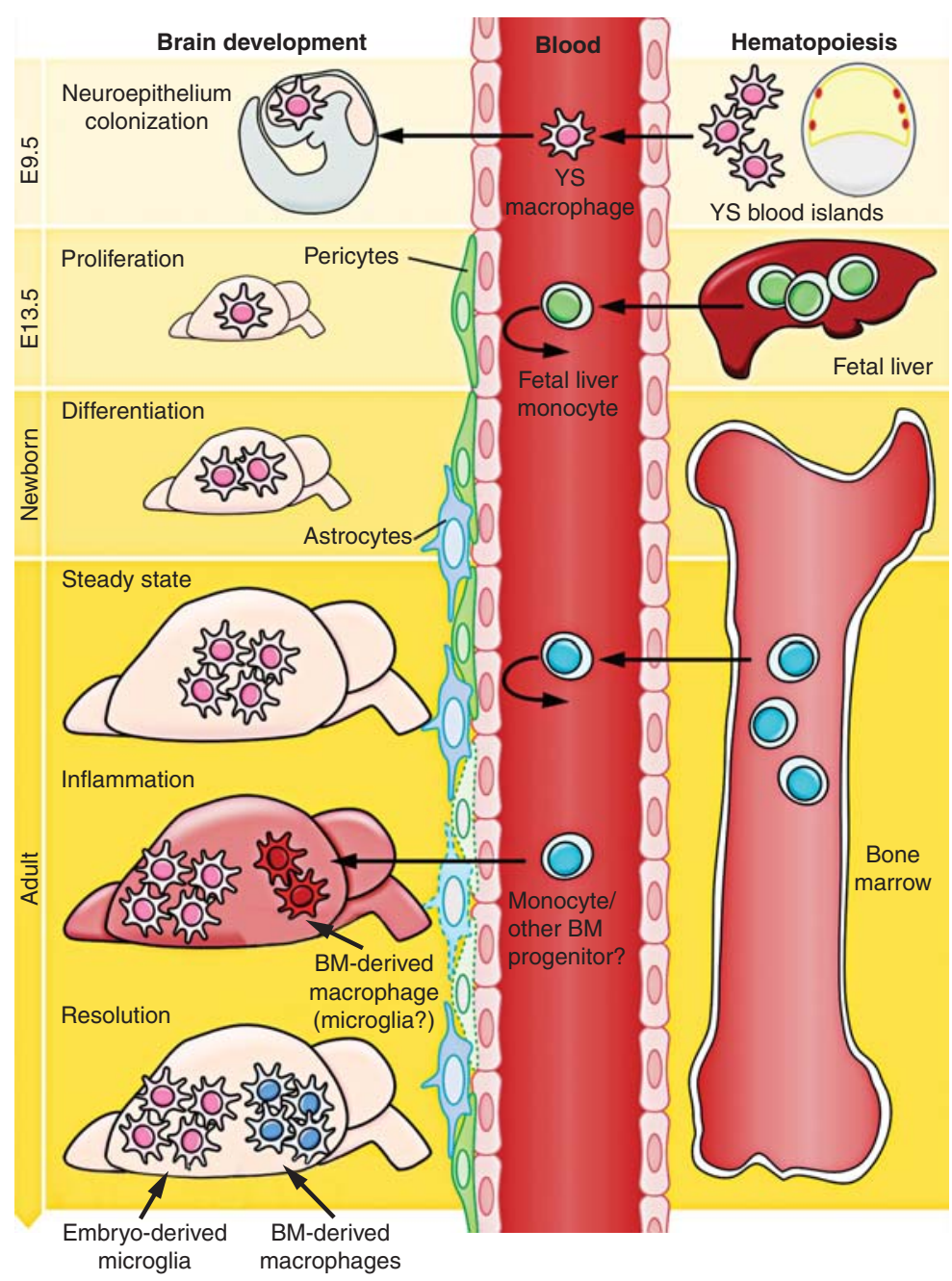

Figure 1. Brain development and microglial ontogeny. Primitive macrophages generated in the yolk sac (YS) blood islands around E8.0 spread into the embryos at the onset of blood circulation established around E8.5 and colonize the neuroepithelium from E9.0/E9.5, giving rise to embryonic microglia. In parallel, definitive hematopoiesis arises in the AGM and gives rise to progenitors that colonize the fetal liver (FL) from E10.5. The bloodbrain barrier (BBB) starts to form from E13.5 and may isolate the developing brain from the contribution of FL and, later, of bone marrow (BM) hematopoiesis. Embryonic microglial cells expand, colonize the whole CNS, and will maintain themselves until adulthood via local proliferation during late gestation and postnatal development, as well as in the injured adult brain in reaction to inflammation. Nevertheless, under certain inflammatory conditions found, for example, after BM transplantation, the recruitment of BM-derived progenitors can supplement the microglial population to some extent.

Recent studies formally confirmed the YS origin of microglia using a range of different strategies (Ginhoux et al. 2010; Kierdorf et al. 2013a), including a fate-mapping mouse model, expressing a fluorescent protein exclusively in YS progenitors and their progeny, including YS macrophages (Ginhoux et al. 2010). Briefly, this mouse model was designed to express a tamoxifen-activated MER-Cre-MER recombinase gene under the control of one of the endogenous promoters of the runt-related transcription factor 1 (Runx1) locus (Samokhvalov 
et al. 2007). When crossed with a Cre-reporter mouse strain, recombination can be induced in embryos by a single injection of 4-hydroxytamoxifen ( $\left.4^{\prime} \mathrm{OHT}\right)$ into pregnant females. Active recombination in these knockin mice occurs in a short time frame, which does not exceed 12-h postinjection, and leads to irreversible expression of fluorescent protein in Runx1 ${ }^{+}$cells and their progeny (Samokhvalov et al. 2007). Although both YS and FL hematopoietic progenitors express Runx1, YS progenitors are the only Runx1 ${ }^{+}$cells present at E7.5, and, so, injection of $4^{\prime} \mathrm{OHT}$ at this time specifically and irreversibly tags YS progenitors and their progeny, but not FL-derived progeny. In contrast, injection of tamoxifen at E8.5 or later will favor the tagging of AGM-derived hematopoietic progenitors and not the YS progenitors (North et al. 1999; Samokhvalov et al. 2007). Thus, if microglia were predominantly derived from YS-tagged progenitors, they should express enhanced yellow fluorescent protein (eYFP) in the adult CNS when $4^{\prime} \mathrm{OHT}$ is injected at E7.25 and not at E8.5. Strikingly, the relative number of tagged microglia in mice injected at E7.25 was much greater than that of blood monocytes or other circulating leukocytes (Ginhoux et al. 2010). In contrast, the relative number of tagged microglia in mice injected from E8.0 onward decreased dramatically, reaching undetectable levels in mice injected as close as E8.5, whereas the relative number of $\mathrm{eYFP}^{+}$leukocytes, including monocytes, increased progressively in adult blood. Further confirmation of the YS origin of microglia later came from another study using myeloid-specific CSF-1R-Cre mice (Schulz et al. 2012). Importantly, this study also highlighted further differences between primitive and definitive hematopoiesis, showing that the latter relies on the transcription factor myeloblastosis (MYB), whereas YS-derived macrophages are MYB independent, but PU.1 dependent (Schulz et al. 2012), as described earlier (Sumner et al. 2000). This is in contrast to a previous study, which reported that mice with null mutations in PU.1 had normal numbers of Csf-1r ${ }^{+}$phagocytes at E11.5 (Lichanska et al. 1999). This further underlines the fact that YS-derived macrophages constitute an inde- pendent lineage, distinct from the progeny of definitive HSCs.

In an another study, we further characterized the early YS progenitor that gives rise to microglia in the brain; we observed c-kit ${ }^{+}$lineage ${ }^{-}$progenitor cells within the YS that have the ability to differentiate into $\mathrm{CX}_{3} \mathrm{CR}^{+}{ }^{+}$microglia in vitro, as well as in vivo (Kierdorf et al. 2013a). These cells also generated Ter $119^{+}$erythrocytes and, thus, represent a common erythromyeloid progenitor (EMP) in the YS. Subsequently, these uncommitted EMPs disappear, and immature $\mathrm{F} 4 / 80^{+} \mathrm{CX}_{3} \mathrm{CR} 1^{-}$and $\mathrm{F} 4 / 80^{+} \mathrm{CX}_{3}$ $\mathrm{CR}^{+}$macrophages develop and seed the surface of the developing brain at E9.0 (Kierdorf et al. 2013a).

A similar pattern of events may occur in humans. In human fetuses, microglia-like cells with a range of morphologies can be detected as early as 13 wk of estimated gestational age (Hutchins et al. 1990). However, it appears that maturation of the microglial compartment is ongoing throughout the majority of gestation. Colonization of the spinal cord begins at around $9 \mathrm{wk}$, the major influx and distribution of microglia commences at about $16 \mathrm{wk}$, and ramified microglia take up to 22 wk to become widely distributed within the intermediate zone (Rezaie and Male 1999; Rezaie et al. 2005). In fact, it is only close to term, at $35 \mathrm{wk}$, that welldifferentiated microglial populations can be detected within the developing human brain (Esiri et al. 1991; Rezaie and Male 2002; Rezaie et al. 2005; Verney et al. 2010).

Importantly, microglial origin is unique among the wide spectrum of tissue macrophage populations (Ginhoux and Jung 2014; Prinz and Priller 2014). Microglia arise predominantly from YS-derived macrophages (Fig. 1) (Ginhoux et al. 2010; Kierdorf et al. 2013a), whereas Langerhans cells originate mainly from FLderived monocytes, but retain a detectable YSderived macrophage (MF) component (Hoeffel et al. 2012). In contrast, alveolar macrophages appear to derive mostly from FL-derived monocytes with minimal lasting contribution from YS-derived macrophages (Guilliams et al. 2013; G Hoeffel, J Chen, Y Lavin et al., in prep.). The origin of other tissue-resident macrophage 
populations in the adult remains to be investigated.

\section{FACTORS DETERMINING THE DEVELOPMENT AND HOMEOSTASIS OF MICROGLIA}

The transcriptional program that controls microglial differentiation is only partially understood (Kierdorf and Prinz 2013). A dramatic reduction in numbers of tissue macrophages, including microglia, occurs in mice that lack the CSF-1R (Dai et al. 2002; Ginhoux et al. 2010; Erblich et al. 2011) and in Csf-1 $1^{\text {op/op }} \mathrm{mu}$ tant mice (Yoshida et al. 1990; Wegiel et al. 1998), which have a natural null mutation in the Csf-1 gene. These studies clearly establish the importance of CSF-1 and its receptor in macrophage homeostasis in vivo (Fig. 2) (Pixley and Stanley 2004), although the precise role of CSF-1 and its receptor during microglial lineage commitment remains controversial. One hypothesis is that CSF-1 drives the microglial differentiation of phagocytic YS macrophages entering the embryo (Metcalf 1985), whereas an alternative theory is that CSF-1 provides a survival signal for the differentiating macrophages and that these surviving cells then respond to an intrinsic developmental program to become mature microglia (Lagasse and Weissman 1997). In favor of the latter hypothesis, macrophages are detected in the YS and the brain rudiment in E10.5 Csf- $1 \mathrm{r}^{-/-}$mice, but not in embryos at E12.5 (Ginhoux et al. 2010; Hoeffel et al. 2012).

Interestingly, the microglial population is more profoundly affected by the absence of the CSF-1R than in the absence of its ligand CSF-1 (Ginhoux et al. 2010), which suggested the possibility of a second ligand for CSF-1R that was later identified as interleukin-34 (IL-34) (Lin et al. 2008). In vitro IL-34 binds the CSF-1R at different regions than CSF-1 and with higher affinity (Chihara et al. 2010); IL-34 is also more highly conserved in mammalian and avian species than CSF-1, suggestive of an important role in macrophage homeostasis (Garceau et al. 2010). Recently, two groups generated IL-34 knockout (KO) mice (Greter et al. 2012; Wang et al. 2012) and reported that, in the brain, de- ficiency of IL-34 led to a significant decrease in microglial cell numbers. Interestingly, IL-34 possesses a spatiotemporal expression pattern that differs from that of CSF-1, permitting complementary activation of the CSF-1R in both embryonic and adult tissues (Wei et al. 2010). Of note, an alternate receptor for IL-34 was recently identified: the receptor-type protein tyrosine phosphatase (PTP)- $\zeta$, which is a cell-surface chondroitin sulfate proteoglycan primarily expressed on neural progenitors and glial cells (Nandi et al. 2013), suggesting that IL-34 may have a wider repertoire of effects within the CNS than previously appreciated. A comparable reduction in microglial cell numbers was also reported in mice deficient for an adaptor protein for CSF-1R, DAP12 (Otero et al. 2009). DAP12 contains an immunoreceptor tyrosine-based activation motif (ITAM) in its cytoplasmic domain and is highly expressed in natural killer (NK) and myeloid cells. In vitro, DAP12 controls proliferation and survival of macrophages stimulated with CSF-1, whereas in vivo in older mice deficient in DAP12 fewer microglia are present, in particular, regions of the CNS, which suggests a role for DAP12 in the long-term homeostasis of microglia. Humans with mutations in the DAP12 gene develop Nasu-Hakola disease, characterized by bone cysts and fractures and psychotic symptoms leading to severe neurodegeneration and encephalopathy (Paloneva et al. 2000).

The transcription factor PU.1, expressed exclusively in hematopoietic cells, is also involved in microglial development (Fig. 2). The Pu.1 (Sfpi-1) gene is a member of the Ets family of transcription factors (Rosenbauer and Tenen 2007), and its disruption leads to multiple hematopoietic abnormalities, including a lack of mature B cells and macrophages (McKercher et al. 1996). In fact, PU.1-deficient mice are not only devoid of circulating monocytes and tissue macrophages (McKercher et al. 1996), but also parenchymal microglia in the brain (Beers et al. 2006). Similar data have been obtained in zebrafish PU.1 mutants that show a complete loss of brain macrophages (Herbomel et al. 2001). In addition, interferon regulatory factor (IRF)-8 has recently been found to regu- 
F. Ginhoux and M. Prinz

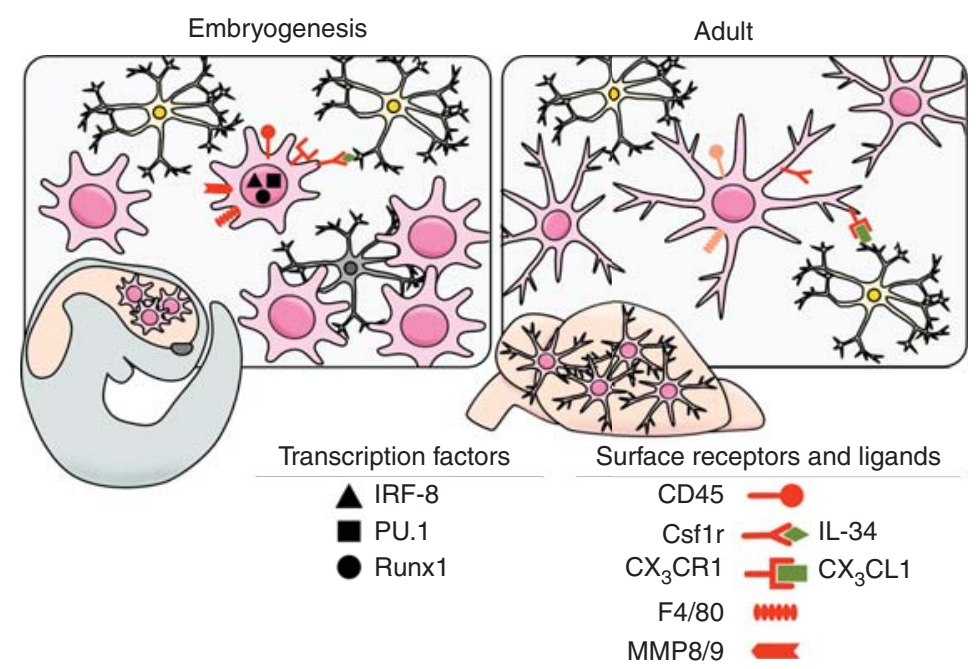

Figure 2. Morphology and markers of embryonic and adult microglia in the mouse. During embryogenesis $(l e f t)$, microglia show an activated and proliferating macrophage-like phenotype. Developing microglia with a round shape migrate throughout the maturing CNS phagocytizing neuronal debris. In adulthood (right), parenchymal microglia build a network of cells interacting with local neurons and display delineated small processes through which they actively survey the interneuronal space. The figure illustrates the precursors, transcription factors (black), and receptors (red) required for each developmental stage.

late the transcriptional programing of microglial development (Kierdorf et al. 2013a). IRF8 is a heterodimeric partner of PU.1 with known roles in the development of $\mathrm{B}$ cells and myeloid cells in the BM (Holtschke et al. 1996). We recently found that YS-derived $\mathrm{F} 4 / 80^{+} \mathrm{CX}_{3} \mathrm{CR} 1^{+}$ macrophages were dependent on the presence of IRF-8 for their early development, whereas other myeloid transcription factors, including MYB, ID2, BATF3, and KLF4, were redundant (Fig. 2) (Kierdorf et al.2013a). Consequently, microglial density was significantly reduced in adult mice lacking IRF-8 (Kierdorf et al. 2013a). Moreover, it now seems that IRF-8 may have a role during the activation of adult microglia (Horiuchi et al. 2012; Masuda et al. 2012; Minten et al. 2012).

\section{THE ADULT MICROGLIAL POPULATION: SELF-RENEWAL RATHER THAN REPLENISHMENT BY THE BLOOD}

\section{During Homeostasis}

Within the first week after birth, the microglial population expands so dramatically (Alliot et al.
1999; Tambuyzer et al. 2009) that it was presumed that the proliferation of embryonic microglial cells alone could not account for such a steep increase in numbers, and so there must be a fresh influx of cells from another compartment. As initially suggested by Del Rio-Ortega, blood monocytes were believed to invade the CNS in the perinatal period and give rise to microglia, replacing the embryonic microglial cells. Several studies supported this hypothesis, notably an early report (Ling 1976) in which round, amoeboid, phagocytic cells were seen in rat corpus callosum during the first few days of life and then disappeared coincident with the appearance of ramified microglia. However, this view has been radically revised in recent years; unequivocal evidence from fate-mapping mouse models revealed that microglia are not BM-derived under homeostatic conditions, but originate from the embryonic YS (Ginhoux et al. 2010). Furthermore, new myeloid-specific gene-targeting approaches that focused on the chemokine receptor $\mathrm{CX}_{3} \mathrm{CR} 1$ have, for the first time, enabled the study of the kinetics of true homeostatic microglial turnover without the 
need for irradiation or chemotherapy (Goldmann et al. 2013; Yona et al. 2013). Using this technique, microglia were found to be long lived with labeled cells traceable for several months, which further argues against replacement by blood cells. In contrast, short-lived circulating Ly- $6 C^{\text {hi }}$ and Ly-6C $C^{\text {lo }}$ monocytes were quickly replaced by their nonlabeled progeny (Goldmann et al. 2013; Yona et al. 2013).

Additional evidence for the lack of significant contribution of monocytes or other BMderived progenitors to the adult microglial pool came from prolonged experiments performed in parabiotic mice, in which two adult congenic mice undergo surgery to physically link their circulatory systems. In reality, even after up to 12 months of parabiosis, although monocytes in the blood of the parabionts originate from both animals, microglia remained totally of host origin, clearly illustrating the absence of contribution of monocytes or BM-derived cells to the CNS microglial population (Ajami et al. 2007, 2011; Ginhoux et al. 2010; Hashimoto et al. 2013).

Taken together, these new genetic approaches helped to firmly establish the major features of microglial population, namely, that they are long lived in vivo and not replaced by peripheral cells from the circulation, but are able to perform context-dependent self-renewal to ensure population maintenance.

\section{During Disease}

One of the most pressing questions in the field of microglial research during recent years has been whether "BM-derived microglia" exist in the adult brain and, if so, whether they are functional. The answer could have profound clinical implications because it determines whether it might be possible to use peripheral microglial precursors as carriers for neuroprotective or immune-modulatory genes into the diseased CNS to treat conditions, such as amyotrophic lateral sclerosis (ALS), Alzheimer's disease (AD), and Parkinson's disease (PD) (Prinz et al. 2011; Prinz and Priller 2014).

The first seminal cell transplantation experiments in rats showed that, following BM trans- plantation, it was only perivascular macrophages that were replaced and not those cells with ramified microglial characteristics in the parenchyma (Hickey and Kimura 1988). Similar results were seen in female patients who underwent sex-mismatched BM transplantation and were subsequently examined for the engraftment of Y-chromosome-positive microglial cells; donor-derived perivascular macrophages were present, but no parenchymal microglia could be detected (Unger et al. 1993). Although informative, all these studies relied on immunohistochemical approaches, which are substantially less sensitive than modern cell transfer experiments using genetically labeled cells. Priller et al. (2001) were among the first who used hematopoietic cells transduced to express green fluorescent protein (GFP) to ask about the long-term fate of myeloid cells in the murine CNS after whole body irradiation and BM transplantation (Fig. 3). They found GFP-expressing parenchymal microglia deep in the cerebellum, striatum, and hippocampus several weeks after transplantation (Eglitis and Mezey 1997; Priller et al. 2001). Despite the differences to the other studies mentioned above, the concept of BMderived phagocytes in the CNS was born. In the following years, a plethora of publications appeared that examined the assumed function and fate of BM-derived mononuclear phagocytes in different neurological models using similar experimental paradigms. Remarkably, CNS infiltration of BM-derived phagocytes was also shown in animal models of disease with no obvious BBB damage, such as ALS (Solomon et al. 2006), AD (Malm et al. 2005; Simard et al. 2006; Mildner et al. 2011), scrapie (Priller et al. 2006), and many more (Priller et al. 2001; Djukic et al. 2006). However, later studies elegantly showed that the irradiation regimen used to prepare recipient animals for BM transplants is necessary for the recruitment and differentiation of BM cells into microglia-like cells (Fig. 3) (Ajami et al. 2007; Mildner et al. 2007, 2011). Importantly, Mildner showed that recipient mice, in which the CNS was shielded to protect from the irradiation and associated release of proinflammatory cytokines and chemokines, did not experience a significant invasion 
F. Ginhoux and M. Prinz

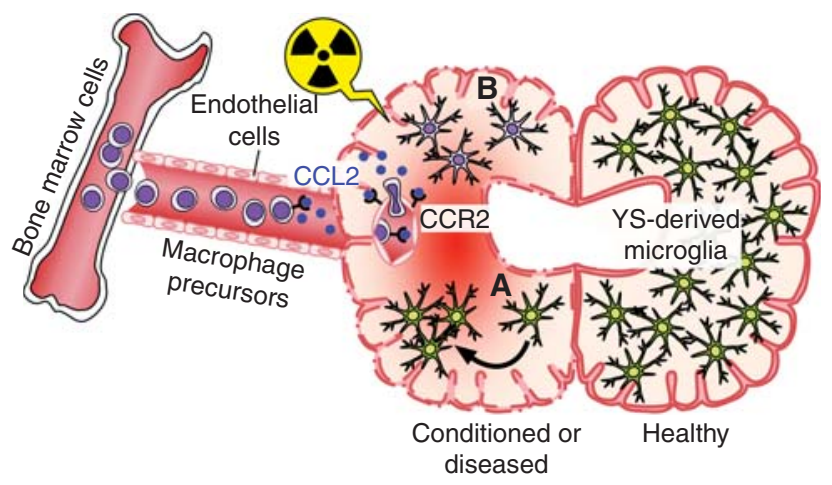

Figure 3. Formation of BM-derived microglia in the adult mouse brain. Postnatal BM-derived microglia form only under defined host conditions in the CNS. BM cells (left) are released into the bloodstream in a chemokine receptor (CCR)-2-dependent fashion and may enter the conditioned CNS. Local conditioning of the CNS can occur via irradiation and neurodegeneration, which lead to both disruption of the BBB and induction of chemokines, such as CCL2, thus, allowing engraftment of BM-derived macrophages. (A) YS-derived microglia (green) perform self-renewal by undergoing proliferation (indicated by an arrow), and (B) BM-derived phagocyte (purple).

of BM-derived cells into the brain in contrast to the unshielded mice (Mildner et al. 2007). Beyond the irradiation issue, these data also suggest that microglial engraftment from the blood requires preconditioning of the CNS that likely disrupts the BBB. Additional clarity came from experiments in parabiotic mice, which enabled the study of the turnover of hematopoietic cells for prolonged periods without the need for irradiation (Ajami et al. 2007). Ajami used such mice to show that, in contrast to irradiated and transplanted mice, there was no microglial progenitor recruitment from the circulation in either denervation or CNS neurodegenerative disease. Intriguingly, if just one parabiont was irradiated, no further contribution from the other parabiont occurred, in apparent contradiction to the results of Mildner. However, Ajami further clarified that, although irradiation is required for donor cells to engraft, it is not sufficient; another important but often overlooked requirement is the artificial and concomitant introduction of a critical number of donor BM cells into the blood circulation (where they are not normally found). This, in conjunction with the inflammation of the $\mathrm{BBB}$ caused by irradiation, creates the unique nonphysiological situation that is required for the BM-to-microglia pathway to prevail (Diserbo et al. 2002; Li et al. 2004; Capotondo et al. 2012). Taking this work further, the same group recently used a similar approach, combining parabiosis and myeloablation, to show that recruited monocytes do not persist in the CNS and, therefore, even under these specific conditions, do not stably contribute to the resident microglial pool (Ajami et al. 2011). However, recruited short-lived monocytes are essential drivers of disease severity in multiple sclerosis (MS) and the experimental mouse model of autoimmune encephalomyelitis (EAE) (King et al. 2009; Mildner et al. 2009). In conclusion, BM-derived microglia can engraft into the diseased brain and become an integral part of the cellular network in the CNS only under specific nonphysiological conditions. These specific conditions include irradiation and chemotherapeutic regimes, for example, the application of myeloablating agents, which all (1) alter the integrity of the BBB, and (2) induce local production of myeloattracting chemokines, such as CCL2 (Boettcher et al. 2008; Lampron et al. 2012; Kierdorf et al. 2013b). Taken together, these data also clearly indicate that BM-derived nonmonocytic cells are able to permanently engraft to the diseased brain, whereas shortlived monocytes are only transiently recruited to the CNS. 


\section{CONCLUSION}

Altogether, these seminal studies established that microglia arise from embryonic hematopoietic precursors that seed the CNS before birth and, more importantly, before the onset of BM hematopoiesis. It is now accepted that microglia derive from unique embryonic precursors, the YS macrophages, which are not found in the $\mathrm{BM}$ as predicted earlier by the founder of the microglial field, Pío del Río-Hortega. This knowledge has far-reaching implications for the understanding of microglial functions in CNS development. First, the conservation of primitive macrophages and their YS derivation, both throughout evolution and across diverse species, suggests that microglia play an important physiological role in the development of the CNS. Furthermore, microglial cells are present during all stages of brain development, including the early prenatal stages of neuronal circuit building, as well as the postnatal stage of synapse elimination. This implies a functional niche for microglia in the development of neuronal circuits of the brain and proposes intriguing possibilities regarding the integrated development of the neural and immune systems.

\section{ACKNOWLEDGMENTS}

We apologize to all colleagues whose work was was not cited owing to space constraints. We thank Dr. L. Robinson for critical review and editing of the manuscript. F.G. is supported by a Singapore Immunology Network core grant. M.P. is supported by the Federal Ministry of Education and Research (BMBF)-funded competence network of multiple sclerosis (KKNMS), the Gemeinnützige Hertie-Stiftung (GHST), the Fritz Thyssen Stiftung, the competence network of neurodegenerative disorders (KNDD), and the The Deutsche Forschungsgemeinschaft (SFB 992, FOR1336).

\section{REFERENCES}

Ajami B, Bennett JL, Krieger C, Tetzlaff W, Rossi FM. 2007 Local self-renewal can sustain CNS microglia maintenance and function throughout adult life. Nat Neurosci 10: $1538-1543$.
Ajami B, Bennett JL, Krieger C, McNagny KM, Rossi FM. 2011. Infiltrating monocytes trigger EAE progression, but do not contribute to the resident microglia pool. Nat Neurosci 14: 1142-1149.

Akiyama H, McGeer PL. 1990. Brain microglia constitutively express $\beta-2$ integrins. J Neuroimmunol 30: 81-93.

Alliot F, Lecain E, Grima B, Pessac B. 1991. Microglial progenitors with a high proliferative potential in the embryonic and adult mouse brain. Proc Natl Acad Sci 88: 15411545.

Alliot F, Godin I, Pessac B. 1999. Microglia derive from progenitors, originating from the yolk sac, and which proliferate in the brain. Brain Res Dev Brain Res 117: 145-152.

Aschoff L. 1924. Das retikuloendotheliale system [The reticuloendothelial system]. Erg Inn Med Kinderheilk 26: S1S117.

Ashwell K. 1990. Microglia and cell death in the developing mouse cerebellum. Brain Res Dev Brain Res 55: 219-230.

Ashwell KW, Waite PM. 1991. Cell death in the developing trigeminal nuclear complex of the rat. Brain Res Dev Brain Res 63: 291-295.

Beers DR, Henkel JS, Xiao Q, Zhao W, Wang J, Yen AA, Siklos L, McKercher SR, Appel SH. 2006. Wild-type microglia extend survival in PU.1 knockout mice with familial amyotrophic lateral sclerosis. Proc Natl Acad Sci 103: $16021-16026$.

Bertrand JY, Jalil A, Klaine M, Jung S, Cumano A, Godin I. 2005. Three pathways to mature macrophages in the early mouse yolk sac. Blood 106: 3004-3011.

Bessis A, Béchade C, Bernard D, Roumier A. 2007. Microglial control of neuronal death and synaptic properties. Glia 55: 233-238.

Bialas AR, Stevens B. 2013. TGF- $\beta$ signaling regulates neuronal C1q expression and developmental synaptic refinement. Nat Neurosci 16: 1773-1782.

Blank T, Prinz M. 2013. Microglia as modulators of cognition and neuropsychiatric disorders. Glia 61: 62-70.

Boettcher C, Ulbricht E, Helmlinger D, Mack AF, Reichenbach A, Wiedemann P, Wagner HJ, Seeliger MW, Bringmann A, Priller J. 2008. Long-term engraftment of systemically transplanted, gene-modified bone marrowderived cells in the adult mouse retina. Br J Ophthalmol 92: $272-275$.

Butovsky O, Siddiqui S, Gabriely G, Lanser AJ, Dake B, Murugaiyan G, Doykan CE, Wu PM, Gali RR, Iyer LK, et al. 2012. Modulating inflammatory monocytes with a unique microRNA gene signature ameliorates murine ALS. J Clin Invest 122: 3063-3087.

Capotondo A, Milazzo R, Politi LS, Quattrini A, Palini A, Plati T, Merella S, Nonis A, di Serio C, Montini E, et al. 2012. Brain conditioning is instrumental for successful microglia reconstitution following hematopoietic stem cell transplantation. Proc Natl Acad Sci 109: 1501815023.

Chan WY, Kohsaka S, Rezaie P. 2007. The origin and cell lineage of microglia: New concepts. Brain Res Rev 53: 344-354.

Chihara T, Suzu S, Hassan R, Chutiwitoonchai N, Hiyoshi M, Motoyoshi K, Kimura F, Okada S. 2010. IL-34 and $\mathrm{M}$-CSF share the receptor Fms but are not identical in 
biological activity and signal activation. Cell Death Differ 17: 1917-1927.

Chiu IM, Morimoto ETA, Goodarzi H, Liao JT, O'Keeffe S, Phatnani HP, Muratet M, Carroll MC, Levy S, Tavazoie S, et al. 2013. A neurodegeneration-specific gene-expression signature of acutely isolated microglia from an amyotrophic lateral sclerosis mouse model. Cell Rep 4: 385-401.

Cumano A, Godin I. 2007. Ontogeny of the hematopoietic system. Annu Rev Immunol 25: 745-785.

Dai X-M, Ryan GR, Hapel AJ, Dominguez MG, Russell RG, Kapp S, Sylvestre V, Stanley ER. 2002. Targeted disruption of the mouse colony-stimulating factor 1 receptor gene results in osteopetrosis, mononuclear phagocyte deficiency, increased primitive progenitor cell frequencies, and reproductive defects. Blood 99: 111-120.

Davalos D, Grutzendler J, Yang G, Kim JV, Zuo Y, Jung S, Littman DR, Dustin ML, Gan WB. 2005. ATP mediates rapid microglial response to local brain injury in vivo. Nat Neurosci 8: $752-758$.

del Río-Hortega P. 1932. Microglia. In Cytology and cellular pathology of the nervous system (ed. Penfield W), Vol. 2, pp. 483-534. P.B. Hoeber, New York.

del Río-Hortega P. 1939. The microglia. Lancet 233: $1023-$ 1026.

Dijkstra CD, Döpp EA, Joling P, Kraal G. 1985. The heterogeneity of mononuclear phagocytes in lymphoid organs: Distinct macrophage subpopulations in the rat recognized by monoclonal antibodies ED1, ED2 and ED3. Immunology 54: 589-599.

Diserbo M, Agin A, Lamproglou I, Mauris J, Staali F, Multon E, Amourette C. 2002. Blood-brain barrier permeability after $\gamma$ whole-body irradiation: An in vivo microdialysis study. Can J Physiol Pharmacol 80: 670-678.

Djukic M, Mildner A, Schmidt H, Czesnik D, Bruck W, Priller J, Nau R, Prinz M. 2006. Circulating monocytes engraft in the brain, differentiate into microglia and contribute to the pathology following meningitis in mice. Brain 129: 2394-2403.

Eglitis MA, Mezey E. 1997. Hematopoietic cells differentiate into both microglia and macroglia in the brains of adult mice. Proc Natl Acad Sci 94: 4080-4085.

Erblich B, Zhu L, Etgen AM, Dobrenis K, Pollard JW. 2011. Absence of colony stimulation factor-1 receptor results in loss of microglia, disrupted brain development and olfactory deficits. PloS ONE 6: e26317.

Esiri MM, Izzi al MS, Reading MC. 1991. Macrophages, microglial cells, and HLA-DR antigens in fetal and infant brain. J Clin Pathol 44: 102-106.

Garceau V, Smith J, Paton IR, Davey M, Fares MA, Sester DP, Burt DW, Hume DA. 2010. Pivotal Advance: Avian colony-stimulating factor 1 (CSF-1), interleukin-34 (IL-34), and CSF-1 receptor genes and gene products. J Leukoc Biol 87: 753-764.

Gautier EL, Shay T, Miller J, Greter M, Jakubzick C, Ivanov S, Helft J, Chow A, Elpek KG, Gordonov S, et al. 2012. Geneexpression profiles and transcriptional regulatory pathways that underlie the identity and diversity of mouse tissue macrophages. Nat Immunol 13: 1118-1128.
Geissmann F, Gordon S, Hume DA, Mowat AM, Randolph GJ. 2010. Unravelling mononuclear phagocyte heterogeneity. Nat Rev Immunol 10: 453-460.

Ginhoux F, Jung S. 2014. Monocytes and macrophages: Developmental pathways and tissue homeostasis. Nat Rev Immunol 14: 392-404.

Ginhoux F, Merad M. 2010. Ontogeny and homeostasis of Langerhans cells. Immunol Cell Biol 88: 387-392.

Ginhoux F, Greter M, Leboeuf M, Nandi S, See P, Gokhan S, Mehler MF, Conway SJ, Ng LG, Stanley ER, et al. 2010. Fate mapping analysis reveals that adult microglia derive from primitive macrophages. Science 330: 841-845.

Ginhoux F, Lim S, Hoeffel G, Low D, Huber T. 2013. Origin and differentiation of microglia. Front Cell Neurosci 7: 45.

Goldmann T, Prinz M. 2013. Role of microglia in CNS autoimmunity. Clin Dev Immunol 2013: 208093-208098.

Goldmann T, Wieghofer P, Müller PF, Wolf Y, Varol D, Yona S, Brendecke SM, Kierdorf K, Staszewski O, Datta M, et al. 2013. A new type of microglia gene targeting shows TAK1 to be pivotal in CNS autoimmune inflammation. Nat Neurosci 16: 1618-1626.

Gordon S. 2002. Pattern recognition receptors: Doubling up for the innate immune response. Cell 111: 927-930.

Gordon S, Taylor PR. 2005. Monocyte and macrophage heterogeneity. Nat Rev Immunol 5: 953-964.

Greter M, Lelios I, Pelczar P, Hoeffel G, Price J, Leboeuf M, Kündig TM, Frei K, Ginhoux F, Merad M, et al. 2012. Stroma-derived interleukin-34 controls the development and maintenance of langerhans cells and the maintenance of microglia. Immunity 37: 1050-1060.

Guilliams M, De Kleer I, Henri S, Post S, Vanhoutte L, De Prijck S, Deswarte K, Malissen B, Hammad H, Lambrecht BN. 2013. Alveolar macrophages develop from fetal monocytes that differentiate into long-lived cells in the first week of life via GM-CSF. J Exp Med 210: 1977-1992.

Hanisch U-K, Kettenmann H. 2007. Microglia: Active sensor and versatile effector cells in the normal and pathologic brain. Nat Neurosci 10: 1387-1394.

Hashimoto D, Chow A, Noizat C, Teo P, Beasley MB, Leboeuf M, Becker CD, See P, Price J, Lucas D, et al. 2013. Tissue-resident macrophages self-maintain locally throughout adult life with minimal contribution from circulating monocytes. Immunity 38: 792-804.

Herbomel P, Thisse B, Thisse C. 2001. Zebrafish early macrophages colonize cephalic mesenchyme and developing brain, retina, and epidermis through a M-CSF receptordependent invasive process. Dev Biol 238: 274-288.

Hickey WF, Kimura H. 1988. Perivascular microglial cells of the CNS are bone marrow-derived and present antigen in vivo. Science 239: 290-292.

Hickman SE, Kingery ND, Ohsumi TK, Borowsky ML, Wang L-C, Means TK, Khoury El J. 2013. The microglial sensome revealed by direct RNA sequencing. Nat Neurosci 16: 1896-1905.

Hoeffel G, Wang Y, Greter M, See P, Teo P, Malleret B, Leboeuf M, Low D, Oller G, Almeida F, et al. 2012. Adult Langerhans cells derive predominantly from embryonic fetal liver monocytes with a minor contribution of yolk sac-derived macrophages. J Exp Med 209: 1167-1181.

Holtschke T, Löhler J, Kanno Y, Fehr T, Giese N, Rosenbauer F, Lou J, Knobeloch KP, Gabriele L, Waring JF, et al. 1996. 
Immunodeficiency and chronic myelogenous leukemialike syndrome in mice with a targeted mutation of the ICSBP gene. Cell 87: 307-317.

Horiuchi M, Wakayama K, Itoh A, Kawai K, Pleasure D, Ozato K, Itoh T. 2012. Interferon regulatory factor 8/ interferon consensus sequence binding protein is a critical transcription factor for the physiological phenotype of microglia. J Neuroinflamm 9: 227.

Hughes V. 2012. Microglia: The constant gardeners. Nature 485: $570-572$.

Hume DA, Perry VH, Gordon S. 1983. Immunohistochemical localization of a macrophage-specific antigen in developing mouse retina: Phagocytosis of dying neurons and differentiation of microglial cells to form a regular array in the plexiform layers. J Cell Biol 97: 253-257.

Hutchins KD, Dickson DW, Rashbaum WK, Lyman WD. 1990. Localization of morphologically distinct microglial populations in the developing human fetal brain: Implications for ontogeny. Brain Res Dev Brain Res 55: 95-102.

Kaufmann SHE. 2008. Immunology's foundation: The 100year anniversary of the Nobel Prize to Paul Ehrlich and Elie Metchnikoff. Nat Immunol 9: 705-712.

Kierdorf K, Prinz M. 2013. Factors regulating microglia activation. Front Cell Neurosci 7: 44.

Kierdorf K, Erny D, Goldmann T, Sander V, Schulz C, Perdiguero EG, Wieghofer P, Heinrich A, Riemke P, Hölscher C, et al. 2013a. Microglia emerge from erythromyeloid precursors via $\mathrm{Pu} .1$ - and Irf-8-dependent pathways. Nat Neurosci 16: 273-280.

Kierdorf K, Katzmarski N, Haas CA, Prinz M. 2013b. Bone marrow cell recruitment to the brain in the absence of irradiation or parabiosis bias. PloS ONE 8: e58544.

King IL, Dickendesher TL, Segal BM. 2009. Circulating Ly- $6 \mathrm{C}^{+}$myeloid precursors migrate to the CNS and play a pathogenic role during autoimmune demyelinating disease. Blood 113: 3190-3197.

Koushik SV, Wang J, Rogers R, Moskophidis D, Lambert NA, Creazzo TL, Conway SJ. 2001. Targeted inactivation of the sodium-calcium exchanger ( $\mathrm{Ncxl}$ ) results in the lack of a heartbeat and abnormal myofibrillar organization. FASEB J 15: 1209-1211.

Lagasse E, Weissman IL. 1997. Enforced expression of Bcl-2 in monocytes rescues macrophages and partially reverses osteopetrosis in op/op mice. Cell 89: 1021-1031.

Lampron A, Lessard M, Rivest S. 2012. Effects of myeloablation, peripheral chimerism, and whole-body irradiation on the entry of bone marrow-derived cells into the brain. Cell Transplant 21: 1149-1159.

Lawson LJ, Perry VH, Dri P, Gordon S. 1990. Heterogeneity in the distribution and morphology of microglia in the normal adult mouse brain. Neuroscience 39: 151-170.

Lehnardt S. 2010. Innate immunity and neuroinflammation in the CNS: The role of microglia in Toll-like receptormediated neuronal injury. Glia 58: 253-263.

Li YQ, Chen P, Jain V, Reilly RM, Wong CS. 2004. Early radiation-induced endothelial cell loss and blood-spinal cord barrier breakdown in the rat spinal cord. Radiat Res 161: $143-152$.

Lichanska AM, Hume DA. 2000. Origins and functions of phagocytes in the embryo. Exp Hematol 28: 601-611.
Lichanska AM, Browne CM, Henkel GW, Murphy KM, Ostrowski MC, McKercher SR, Maki RA, Hume DA. 1999. Differentiation of the mononuclear phagocyte system during mouse embryogenesis: The role of transcription factor PU.1. Blood 94: 127-138.

Lin H, Lee E, Hestir K, Leo C, Huang M, Bosch E, Halenbeck R, Wu G, Zhou A, Behrens D, et al. 2008. Discovery of a cytokine and its receptor by functional screening of the extracellular proteome. Science 320: 807-811.

Ling EA. 1976. Some aspects of amoeboid microglia in the corpus callosum and neighbouring regions of neonatal rats. J Anat 121: 29-45.

Malm TM, Koistinaho M, Pärepalo M, Vatanen T, Ooka A, Karlsson S, Koistinaho J. 2005. Bone-marrow-derived cells contribute to the recruitment of microglial cells in response to $\beta$-amyloid deposition in APP/PS1 double transgenic Alzheimer mice. Neurobiol Dis 18: 134-142.

Masuda T, Tsuda M, Yoshinaga R, Tozaki-Saitoh H, Ozato K, Tamura T, Inoue K. 2012. IRF-8 is a critical transcription factor for transforming microglia into a reactive phenotype. Cell Rep 1: 334-340.

McKercher SR, Torbett BE, Anderson KL, Henkel GW, Vestal DJ, Baribault H, Klemsz M, Feeney AJ, Wu GE, Paige CJ, et al. 1996. Targeted disruption of the PU.1 gene results in multiple hematopoietic abnormalities. EMBO J 15: 5647-5658.

Metcalf D. 1985. The granulocyte-macrophage colony-stimulating factors. Science 229: 16-22.

Mildner A, Schmidt H, Nitsche M, Merkler D, Hanisch U-K, Mack M, Heikenwalder M, Brück W, Priller J, Prinz M. 2007. Microglia in the adult brain arise from Ly-6ChiCCR $2^{+}$monocytes only under defined host conditions. Nat Neurosci 10: 1544-1553.

Mildner A, Mack M, Schmidt H, Brück W, Djukic M, Zabel MD, Hille A, Priller J, Prinz M. 2009. CCR2 ${ }^{+}$Ly-6Chi monocytes are crucial for the effector phase of autoimmunity in the central nervous system. Brain 132: $2487-$ 2500.

Mildner A, Schlevogt B, Kierdorf K, Böttcher C, Erny D, Kummer MP, Quinn M, Brück W, Bechmann I, Heneka MT, et al. 2011. Distinct and non-redundant roles of microglia and myeloid subsets in mouse models of Alzheimer's disease. J Neurosci 31: 11159-11171.

Minghetti L, Levi G. 1998. Microglia as effector cells in brain damage and repair: Focus on prostanoids and nitric oxide. Prog Neurobiol 54: 99-125.

Minten C, Terry R, Deffrasnes C, King NJC, Campbell IL. 2012. IFN regulatory factor 8 is a key constitutive determinant of the morphological and molecular properties of microglia in the CNS. PloS ONE 7: e49851.

Murabe Y, Sano Y. 1982. Morphological studies on neuroglia: VI. Postnatal development of microglial cells. Cell Tissue Res 225: 469-485.

Murabe Y, Sano Y. 1983. Morphological studies on neuroglia: VII. Distribution of "brain macrophages" in brains of neonatal and adult rats, as determined by means of immunohistochemistry. Cell Tissue Res 229: 85-95.

Nandi S, Cioce M, Yeung Y-G, Nieves E, Tesfa L, Lin H, Hsu AW, Halenbeck R, Cheng H-Y, Gokhan S, et al. 2013. Receptor-type protein-tyrosine phosphatase $\zeta$ is a functional receptor for interleukin-34. J Biol Chem 288: 21972-21986. 
Nimmerjahn A, Kirchhoff F, Helmchen F. 2005. Resting microglial cells are highly dynamic surveillants of brain parenchyma in vivo. Science 308: 1314-1318.

North T, Gu TL, Stacy T, Wang Q, Howard L, Binder M, Marin-Padilla M, Speck NA. 1999. Cbfa2 is required for the formation of intra-aortic hematopoietic clusters. Development 126: $2563-2575$.

Orkin SH, Zon LI. 2008. Hematopoiesis: An evolving paradigm for stem cell biology. Cell 132: 631-644.

Otero K, Turnbull IR, Poliani PL, Vermi W, Cerutti E, Aoshi T, Tassi I, Takai T, Stanley SL, Miller M, et al. 2009. Macrophage colony-stimulating factor induces the proliferation and survival of macrophages via a pathway involving DAP12 and $\beta$-catenin. Nat Immunol 10: 734-743.

Paloneva J, Kestilä M, Wu J, Salminen A, Böhling T, Ruotsalainen V, Hakola P, Bakker AB, Phillips JH, Pekkarinen P, et al. 2000. Loss-of-function mutations in TYROBP (DAP12) result in a presenile dementia with bone cysts. Nat Genet 25: 357-361.

Paolicelli RC, Bolasco G, Pagani F, Maggi L, Scianni M, Panzanelli P, Giustetto M, Ferreira TA, Guiducci E, Dumas L, et al. 2011. Synaptic pruning by microglia is necessary for normal brain development. Science 333: $1456-$ 1458.

Perry VH. 1998. A revised view of the central nervous system microenvironment and major histocompatibility complex class II antigen presentation. J Neuroimmunol 90: $113-121$.

Perry VH, Hume DA, Gordon S. 1985. Immunohistochemical localization of macrophages and microglia in the adult and developing mouse brain. Neuroscience 15: 313-326.

Perry VH, Nicoll JAR, Holmes C. 2010. Microglia in neurodegenerative disease. Nat Rev Neurol 6: 193-201.

Pixley FJ, Stanley ER. 2004. CSF-1 regulation of the wandering macrophage: Complexity in action. Trends Cell Biol 14: 628-638.

Priller J, Flügel A, Wehner T, Boentert M, Haas CA, Prinz M, Fernández-Klett F, Prass K, Bechmann I, de Boer BA, et al. 2001. Targeting gene-modified hematopoietic cells to the central nervous system: Use of green fluorescent protein uncovers microglial engraftment. Nat Med 7: 1356-1361.

Priller J, Prinz M, Heikenwalder M, Zeller N, Schwarz P, Heppner FL, Aguzzi A. 2006. Early and rapid engraftment of bone marrow-derived microglia in scrapie. J Neurosci 26: 11753-11762.

Prinz M, Mildner A. 2011. Microglia in the CNS: Immigrants from another world. Glia 59: 177-187.

Prinz M, Priller J. 2014. Microglia and brain macrophages in the molecular age: From origin to neuropsychiatric disease. Nat Rev Neurosci 15: 300-312.

Prinz M, Priller J, Sisodia SS, Ransohoff RM. 2011. Heterogeneity of CNS myeloid cells and their roles in neurodegeneration. Nat Neurosci 14: 1227-1235.

Ransohoff RM, Cardona AE. 2010. The myeloid cells of the central nervous system parenchyma. Nature 468: $253-$ 262.

Ransohoff RM, Perry VH. 2009. Microglial physiology: Unique stimuli, specialized responses. Аппи Rev Immunol 27: 119-145.
Rezaie P, Male D. 1999. Colonisation of the developing human brain and spinal cord by microglia: A review. Microsc Res Tech 45: 359-382.

Rezaie P, Male D. 2002. Mesoglia \& microglia—A historical review of the concept of mononuclear phagocytes within the central nervous system. J Hist Neurosci 11: 325-374.

Rezaie P, Dean A, Male D, Ulfig N. 2005. Microglia in the cerebral wall of the human telencephalon at second trimester. Cereb Cortex 15: 938-949.

Rosenbauer F, Tenen DG. 2007. Transcription factors in myeloid development: Balancing differentiation with transformation. Nat Rev Immunol 7: 105-117.

Samokhvalov IM, Samokhvalova NI, Nishikawa S-I. 2007. Cell tracing shows the contribution of the yolk sac to adult haematopoiesis. Nature 446: 1056-1061.

Schafer DP, Lehrman EK, Kautzman AG, Koyama R, Mardinly AR, Yamasaki R, Ransohoff RM, Greenberg ME, Barres BA, Stevens B. 2012. Microglia sculpt postnatal neural circuits in an activity and complement-dependent manner. Neuron 74: 691-705.

Schlegelmilch T, Henke K, Peri F. 2011. Microglia in the developing brain: From immunity to behaviour. Curr Opin Neurobiol 21: 5-10.

Schulz C, Gomez Perdiguero E, Chorro L, Szabo-Rogers H, Cagnard N, Kierdorf K, Prinz M, Wu B, Jacobsen SE, Pollard JW, et al. 2012. A lineage of myeloid cells independent of $\mathrm{Myb}$ and hematopoietic stem cells. Science 336: 86-90.

Serrats J, Schiltz JC, García-Bueno B, van Rooijen N, Reyes TM, Sawchenko PE. 2010. Dual roles for perivascular macrophages in immune-to-brain signaling. Neuron 65: 94-106.

Simard AR, Soulet D, Gowing G, Julien JP, Rivest S. 2006. Bone marrow-derived microglia play a critical role in restricting senile plaque formation in Alzheimer's disease. Neuron 49: 489-502.

Solomon JN, Lewis C-AB, Ajami B, Corbel SY, Rossi FMV, Krieger C. 2006. Origin and distribution of bone marrow-derived cells in the central nervous system in a mouse model of amyotrophic lateral sclerosis. Glia 53: 744-753.

Squazorni P, Oller G, Hoeffel G, Pont-Lezica, Rostaing P, Low D, Bessis B, Ginhoux F, Garel S. 2014. Microglia modulate wiring of the embryonic forebrain. Cell Rep 8: 1271-1279.

Sumner R, Crawford A, Mucenski M, Frampton J. 2000. Initiation of adult myelopoiesis can occur in the absence of c-Myb whereas subsequent development is strictly dependent on the transcription factor. Oncogene 19: 33353342.

Swinnen N, Smolders S, Avila A, Notelaers K, Paesen R, Ameloot M, Brône B, Legendre P, Rigo J-M. 2013. Complex invasion pattern of the cerebral cortex bymicroglial cells during development of the mouse embryo. Glia 61: $150-163$.

Takahashi K, Naito M, Takeya M. 1996. Development and heterogeneity of macrophages and their related cells through their differentiation pathways. Pathol Int 46: $473-485$. 
Tambuyzer BR, Ponsaerts P, Nouwen EJ. 2009. Microglia: Gatekeepers of central nervous system immunology. $J$ Leukoc Biol 85: 352-370.

Tremblay MÈ, Lowery RL, Majewska AK. 2010. Microglial interactions with synapses are modulated by visual experience. PLoS Biol 8: e1000527.

Unger ER, Sung JH, Manivel JC, Chenggis ML, Blazar BR, Krivit W. 1993. Male donor-derived cells in the brains of female sex-mismatched bone marrow transplant recipients: A Y-chromosome specific in situ hybridization study. J Neuropathol Exp Neurol 52: 460-470.

van Furth R, Cohn ZA. 1968. The origin and kinetics of mononuclear phagocytes. J Exp Med 128: 415-435.

van Furth R, Cohn ZA, Hirsch JG, Humphrey JH, Spector WG, Langevoort HL. 1972. The mononuclear phagocyte system: A new classification of macrophages, monocytes, and their precursor cells. Bull World Health Organ 46: 845-852.

Verney C, Monier A, Fallet-Bianco C, Gressens P. 2010. Early microglial colonization of the human forebrain and possible involvement in periventricular white-matter injury of preterm infants. J Anat 217: 436-448.

Wang Y, Szretter KJ, Vermi W, Gilfillan S, Rossini C, Cella M, Barrow AD, Diamond MS, Colonna M. 2012. IL-34 is a tissue-restricted ligand of CSF1R required for the development of Langerhans cells and microglia. Nat Immunol 13: $753-760$.

Wegiel J, Wisniewski HM, Dziewiatkowski J, Tarnawski M, Kozielski R, Trenkner E, Wiktor-Jedrzejczak W. 1998. Reduced number and altered morphology of microglial cells in colony stimulating factor-1-deficient osteopetrotic op/op mice. Brain Res 804: 135-139.

Wei S, Nandi S, Chitu V, Yeung Y-G, Yu W, Huang M, Williams LT, Lin H, Stanley ER. 2010. Functional overlap but differential expression of CSF-1 and IL-34 in their CSF-1 receptor-mediated regulation of myeloid cells. J Leukoc Biol 88: 495-505.

Yona S, Kim K-W, Wolf Y, Mildner A, Varol D, Breker M, Strauss-Ayali D, Viukov S, Guilliams M, Misharin A, et al. 2013. Fate mapping reveals origins and dynamics of monocytes and tissue macrophages under homeostasis. Immunity 38: 79-91.

Yoshida H, Hayashi S, Kunisada T, Ogawa M, Nishikawa S, Okamura H, Sudo T, Shultz LD. 1990. The murine mutation osteopetrosis is in the coding region of the macrophage colony stimulating factor gene. Nature 345: 442444. 


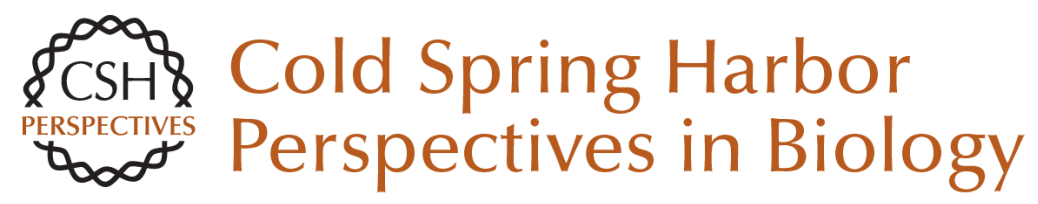

\section{Origin of Microglia: Current Concepts and Past Controversies}

Florent Ginhoux and Marco Prinz

Cold Spring Harb Perspect Biol 2015; doi: 10.1101/cshperspect.a020537 originally published online July 1,2015

\section{Subject Collection Glia}

The Nodes of Ranvier: Molecular Assembly and Maintenance

Matthew N. Rasband and Elior Peles

Microglia in Health and Disease

Richard M. Ransohoff and Joseph El Khoury

The Astrocyte: Powerhouse and Recycling Center Bruno Weber and L. Felipe Barros

Microglia Function in Central Nervous System

Development and Plasticity

Dorothy P. Schafer and Beth Stevens

Transcriptional and Epigenetic Regulation of Oligodendrocyte Development and Myelination in the Central Nervous System

Ben Emery and Q. Richard Lu

Origin of Microglia: Current Concepts and Past

Controversies

Florent Ginhoux and Marco Prinz

Glia Disease and Repair--Remyelination

Robin J.M. Franklin and Steven A. Goldman

Astrocytes in Neurodegenerative Disease

Hemali Phatnani and Tom Maniatis
Oligodendrocyte Development and Plasticity Dwight E. Bergles and William D. Richardson

Oligodendrocytes: Myelination and Axonal

Support Mikael Simons and Klaus-Armin Nave

Drosophila Central Nervous System Glia Marc R. Freeman

Perisynaptic Schwann Cells at the Neuromuscular

Synapse: Adaptable, Multitasking Glial Cells Chien-Ping Ko and Richard Robitaille

Astrocytes Control Synapse Formation, Function, and Elimination Won-Suk Chung, Nicola J. Allen and Cagla Eroglu

Schwann Cell Myelination James L. Salzer

Schwann Cells: Development and Role in Nerve Repair

Kristján R. Jessen, Rhona Mirsky and Alison C. Lloyd

Perineurial Glia

Sarah Kucenas

For additional articles in this collection, see http://cshperspectives.cshlp.org/cgi/collection/

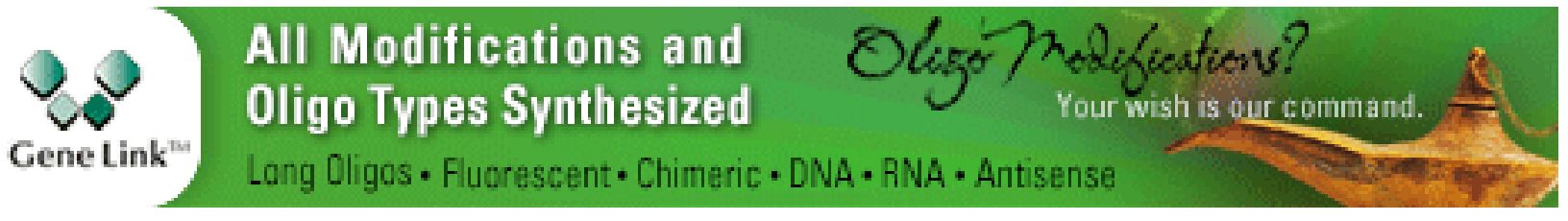

